\title{
Toughness Improvement in Ternary HDPE/PS/PET Polymer Blends with Compatibilizer
}

\author{
K. Dobrovszky, F. Ronkay \\ Department of Polymer Engineering, Faculty of Mechanical Engineering, \\ Budapest University of Technology and Economics \\ Müegyetem rkp. 3, 1111 Budapest, Hungary \\ e-mail: dobrovszky@pt.bme.hu
}

Abstract: Preparing polymer blends is an effective way to develop new raw materials. In the present study, the morphological and mechanical properties were investigated of ternary polymer blends. Immiscible plastics: polyethylene terephthalate (PET), high density polyethylene (HDPE) and polystyrene (PS) were blended, which can be found in postconsumer waste in large quantities and compatibilizer agents were also added to the blend. Three different processing methods, internal mixing, extrusion and injection moulding were used during the production. The results show that the best mechanical properties can be achieved if the ternary polymer blends are produced by extrusion followed by injection moulding or direct injection moulding without prior homogenization, and styrene/ethylene-butylene/styrene copolymer grafted with maleic anhydride (SEBS-g-MA) was also added to the polymer blend.

Keywords: ternary blend, compatibilization, toughness, scanning electron microscopy

\section{Introduction}

Preparing polymer blend - a mixture of at least two macromolecular substances - is an effective way to develop new raw materials, where the favourable properties of the polymers can be tailored for industry [1]. However, in most cases polymers are not compatible with each other, because of their high molecular weight and for thermodynamic reasons [2]. The miscibility between two phases can be described by Flory-Huggins solution theory (Eq. (1)):

$$
\Delta G_{m} / R T=\Phi_{1} / V_{1} \cdot \ln \Phi_{1}+\Phi_{2} / V_{2} \cdot \ln \Phi_{2}+\chi_{12}^{\prime} \cdot \Phi_{1} \Phi_{2}
$$

where $\Delta G_{\mathrm{m}}$ is the change of Gibbs free energy, $R$ is the universal gas constant, $T$ is the temperature, $\Phi_{1}$ and $\Phi_{2}$ are the volume fractions, $V_{1}$ and $V_{2}$ are the molar volume of components " 1 " and " 2 ", $\chi{ }_{12}^{\prime}$ is the dimensionless Flory-Huggins binary interaction parameter [3]. 
It can be also difficult to choose the suitable processing parameters for preparing blends. The improper selection of processing temperature can easily cause degradation in one of the components of blend. Polyolefins, like polyethylene (PE) and polypropylene ( $\mathrm{PP})$ require generally lower melting temperature during the processing than engineering plastics, like polyethylene terephthalate (PET). When two or more plastics are mixed together, usually a heterogeneous morphological structure is formed, that induces low mechanical properties due to the poor interfacial interaction between the components. To achieve good dispersion between the immiscible phases, copolymer or compatibilizer can be added to the polymer blends, in order to obtain a stable and finer morphology structure leading better impact strength properties [4]. Nowadays, nanocomposites have opened a new way in the development of polymer blends and composites. Thus, the tensile strength and Young's modulus can be further increased by using nanoclay like montmorillonite [5].

Ternary polymer blends have gained exceptional attention lately [6-8]. Razavi et al. [6] investigated binary and ternary blends, using recycled HDPE, recycled PS and recycled PET. They found the phases were incompatible with each other, but ternary blend showed a better performance in morphological characteristics and mechanical properties. However, their research did not cover the opportunities of compatibilization. Omonov et al. [7] found a great correlation between the morphology development of blends and the applied reactive compatibilization process. Yen et al. [8] compared two different processing methods to obtain the change of shell-core structure of the dispersed phases. They found, the impact property of blends strongly depends on the thickness of the additive between the phases, which can be controlled by the correct processing.

To achieve the desired mechanical properties in ternary blends, the morphology and the size of the dispersed phases have to be controlled [9]. The most influential factors, during the formation of the microstructure, are the compositional ratio, the viscosity and the interfacial bond between the phases [10]. By combining the effects of these factors, different complex morphological structures can be formed, e.g. tri-continuous phases, bi-continuous structures with one dispersed phase, or a matrix with two dispersed phases, where sometimes one of the components is encapsulated by the other ones [11]. The different morphological structures of ternary blends are presented on Fig. 1. 


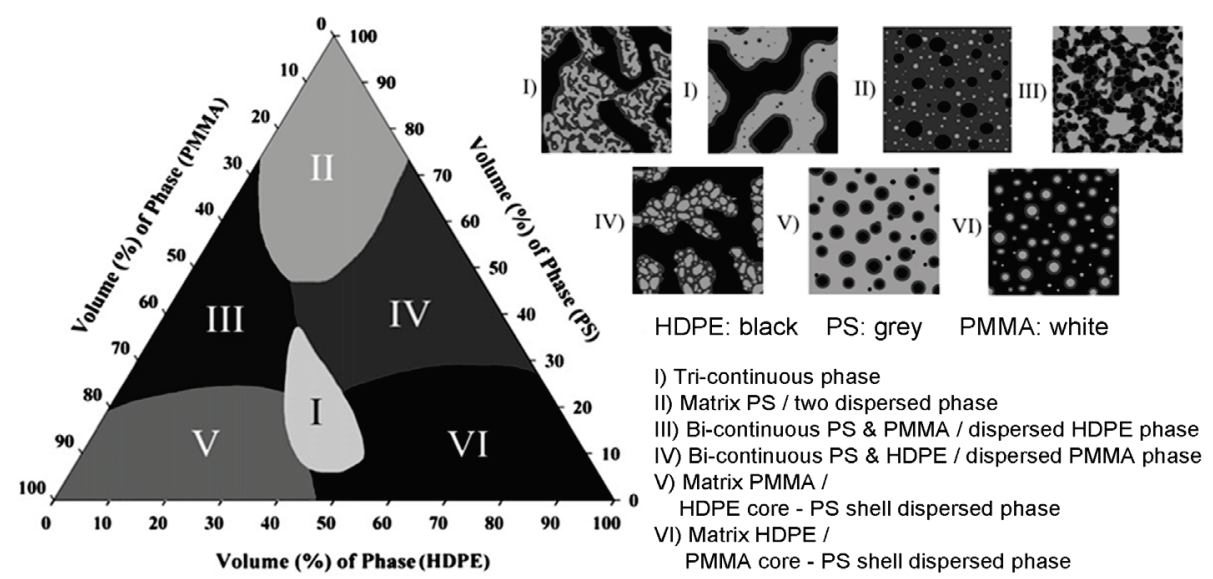

Figure 1. Different morphological states of various ternary blends [11]

Recycling is important because of social demands and regulatory requirements. Recycling of the polymers can be realized in two different ways: separating the waste stream into pure fractions [12], or using additives in order to improve the compatibility between the components [13]. Consequently, this examination of ternary blends can also promote the recycling process of polymers, particularly the area of packaging [14].

The aim of this paper is to present the effects of different blending methods and the changes in mechanical and morphological properties. It would be also important to know the effects of the prior homogenisation on morphology, tensile and impact properties of blends. In the first step, styrene/ethylene-butylene/styrene copolymer grafted with maleic anhydride (SEBS-g-MA), which additive is recommended by previous studies [15-17], was added to the ternary 70/15/15 wt\% HDPE/PS/PET blends in order to improve the impact strength and the elongation at break. Another additive polypropylene grafted with maleic anhydride (PP-g-MA), which is not a recommended additive, was also added to the blends in order to investigate the potential negative effects of an improperly selected additive on tensile and impact properties of blends.

\section{Experimental}

\subsection{Materials}

Three different types of plastics - which can be found in large quantities in postconsumer waste - PET, PS and HDPE were used during the study, where (i) HDPE was Tipelin BA $550-13$ (density $0.955 \mathrm{~g} / \mathrm{cm}^{3}$; MFI $=0.35 \mathrm{~g} / 10 \mathrm{~min}, 190^{\circ} \mathrm{C} / 2.16 \mathrm{~kg}$ ) produced by TVK, (ii) PS was Edistir N 1840 (density $1.05 \mathrm{~g} / \mathrm{cm}^{3}$; MFI=10.0 g/10 min, $200^{\circ} \mathrm{C} / 5.0$ $\mathrm{kg}$ ) produced by Polimeri Europa and (iii) PET was NeoPET 80 (density $1.34 \mathrm{~g} / \mathrm{cm}^{3}$; $\mathrm{T}_{\mathrm{m}}=248^{\circ} \mathrm{C}$ ) produced by neogroup. Two kinds of compatibilizers were added to the ternary polymer blends in $4 \mathrm{wt} \%$ ratio: (i) the maleic anhydride grafted polypropylene (PP-g-MA) was Orevac CA 100 (MFI=10 g/10 min, $190^{\circ} \mathrm{C} / 320 \mathrm{~g} ; \mathrm{T}_{\mathrm{m}}=167^{\circ} \mathrm{C}$ ), produced by Arkema, (ii) the maleic anhydride grafted styrene/ethylenebutylene/styrene copolymer (SEBS-g-MA) was Kraton FG1901X (density $0.91 \mathrm{~g} / \mathrm{cm}^{3}$; $\left.\mathrm{MFI}=22 \mathrm{~g} / 10 \mathrm{~min}, 230^{\circ} \mathrm{C} / 5 \mathrm{~kg}\right)$. 


\subsection{Compoundation and test sample preparation}

70/15/15 wt $\%$ HDPE/PS/PET blends were prepared added with different types of compatibilizers in $4 \mathrm{wt} \%$. The samples were made by three different methods: (i) premixing polymer blends with internal mixer, or (ii) using a twin screw extruder, which are followed by injection moulding after prior homogenization or (iii) making samples directly from the granules by injection moulding without prior homogenization.

PET was dried 6 hours in an air drying oven at $160^{\circ} \mathrm{C}$. A Brabender Plasti-Corder PL2000 was used to prepare the internal mixed HDPE/PS/PET ternary blends (temperature $275^{\circ} \mathrm{C}$, melt-blending time $10 \mathrm{~min}$, mixing speed $20 \mathrm{rpm}$ ), followed by a grinding stage to reach the suitable shape of blends for injection moulding.

The extrusion occurred in a Labtech Scientific LTE 26-44 twin screw extruder with a double circular cross section die with a diameter of $3 \mathrm{~mm}$ (zone temperature from $250^{\circ} \mathrm{C}$ to $275^{\circ} \mathrm{C}$, rotation speed $40 \mathrm{rpm}$ ). The extrudates were cooled down in a water bath, finally a Labtech LZ-120/VS granulator was used to make $3 \mathrm{~mm}$ granules.

To prepare the injection moulded specimens with a cross section of $10 \times 4 \mathrm{~mm}$ an Arburg Allrounder Advance 370S 700-290 was used, with the following parameters: the nozzle temperature was $275^{\circ} \mathrm{C}$, injection flow was $20 \mathrm{~cm}^{3} / \mathrm{s}$, injection volume was 46 $\mathrm{cm}^{3}$, holding pressure was $400 \pm 50 \mathrm{bar}$ - depending on the content of the mixture, the cycle time was $50 \mathrm{~s}$.

\subsection{Test methods}

CEAST Modular Melt Flow Model 7027.000 was used to measure the viscosity in melt volume rate (MVR) of the polymers $\left(275^{\circ} \mathrm{C}, 2.16 \mathrm{~kg}\right)$, according to ISO 1133 .

The tensile tests were performed on a Zwick Z020 Universal Testing equipment with a $10 \mathrm{kN}$ tensile head (test speed $20 \mathrm{~mm} / \mathrm{min}$, clamping distance $100 \mathrm{~mm}$ ). 5 repetitions were done for each composition (according to ISO 527 standard).

Charpy impact strength was measured by a Ceast Resil Impactor Junior impact test machine, with a $15 \mathrm{~J}$ hammer and with an impact speed of $3.4 \mathrm{~m} / \mathrm{s}$, where the distance between the supports was $62 \mathrm{~mm}$. 8 unnotched samples were measured for each composition, with a size of $80 \times 10 \times 4 \mathrm{~mm}$ (according to ISO 179-1).

JEOL JSM 6380LA scanning electron microscopy (SEM) was used at an acceleration voltage of $15 \mathrm{kV}$ in secondary electron imaging mode, to study the morphological structures of the cryogenic fractured surface of blends (gold coating time was $45 \mathrm{~s}$ ).

\section{Results and discussion}

\subsection{Rheology}

The viscosity of polymers can be characterized with MVR in the melt phase. As shown in Table 1. PS had the highest MVR rate, while HDPE can be characterized by low flowability during processing, because this plastic is recommended for blow technologies. This can be confirmed by the fact that the measured MVR value at $275^{\circ} \mathrm{C}$ is very close to the specified value by the manufacturer under the same load (but at 
$190^{\circ} \mathrm{C}$ ). The exact MVR rate of PP-g-MA was difficult to determine by the applied parameters, because the MVR value was more than $100 \mathrm{~cm}^{3} / 10$ min at $275^{\circ} \mathrm{C}$.

Table 1. The measured MVR rates of applied plastics and SEBS-g-MA $\left(275^{\circ} \mathrm{C}, 2.16 \mathrm{~kg}\right)$

\begin{tabular}{|l|c|c|c|c|}
\cline { 2 - 5 } \multicolumn{1}{c|}{} & HDPE & PS & PET & SEBS-g-MA \\
\hline MVR $\left[\mathrm{cm}^{3} / 10 \mathrm{~min}\right]$ & 0.95 & 79.01 & 55.09 & 33.07 \\
\hline
\end{tabular}

\subsection{Morphology investigation by SEM}

The morphologies of the ternary 70/15/15 wt $\%$ HDPE/PS/PET blends, made by different processing methods, are shown on Fig. 2-4. The coarsest morphological structure occurred after internal mixing (Fig. 2.); the finest morphology formed after injection moulding because of the higher shear stress. It can be seen, that extrusion (Fig. 3.) and injection moulding (Fig. 4.) resulted in a fibrous morphology, while internal mixing resulted in an encapsulated structure between the dispersed PS and PET phases. It should be noticed, that due to repeated melting during injection moulding the previous morphology after prior homogenization was decomposed, resulting in the same morphology as presented on Fig. 4.

A finer dispersion occurred in blends containing $4 \mathrm{wt} \%$ SEBS-g-MA, than blends compatibilized with PP-g-MA. This phenomenon can be explained by the chemical interaction between the phases: the styrene block of SEBS-g-MA could miscible with PS, the hydrogenated ethylene-butadiene blocks react well with HDPE and the maleic anhydride groups of SEBS-g-MA could interact with hydroxyl end-groups of PET; resulting in a finer and stable morphology in HDPE/PS/PET blends.
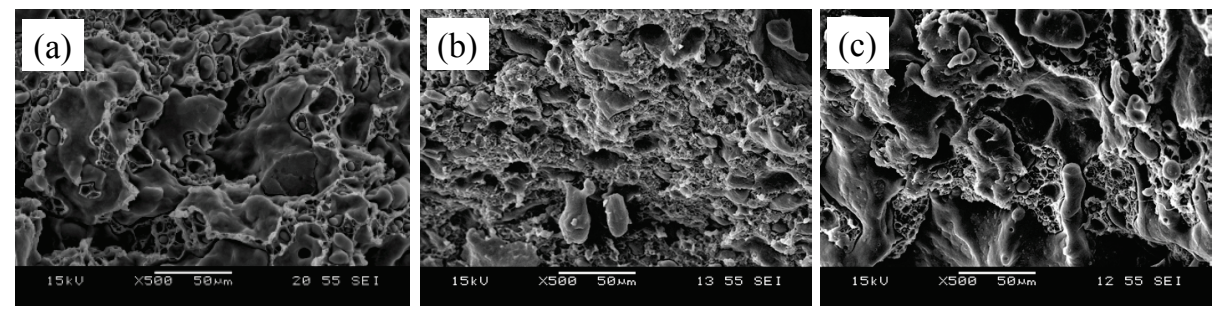

Figure 2. Morphology of internal mixing of 70/15/15 wt\% HDPE/PS/PET ternary blends: (a) without compatibilizer, (b) 4 wt\% SEBS-g-MA, (c) 4 wt $\%$ PP-g-MA
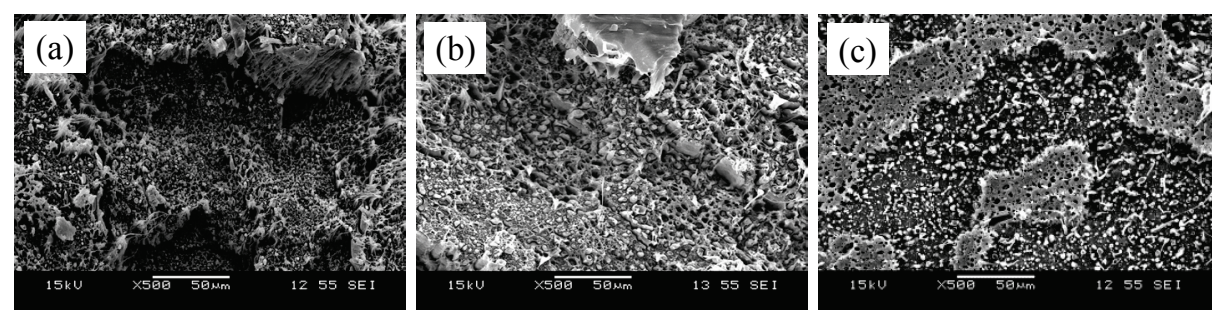

Figure 3. Morphology after extrusion of 70/15/15 wt\% HDPE/PS/PET ternary blends: (a) without compatibilizer, (b) 4 wt\% SEBS-g-MA, (c) 4 wt $\%$ PP-g-MA 

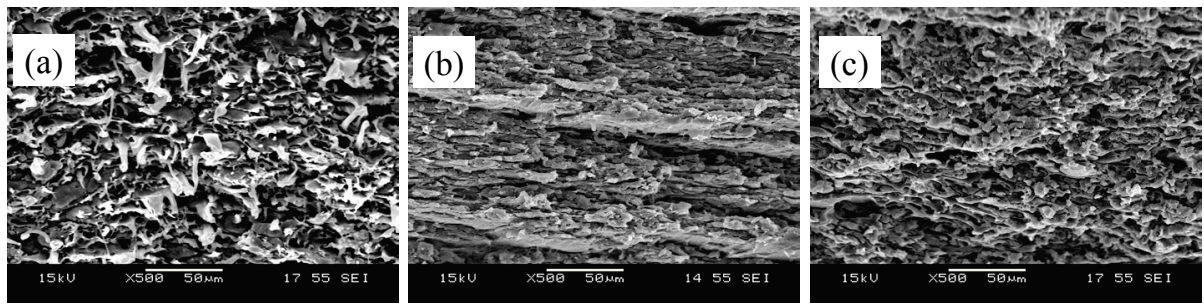

Figure 4. Morphology after injection moulding of 70/15/15 wt\% HDPE/PS/PET ternary blends: (a) without compatibilizer, (b) 4 wt\% SEBS-g-MA, (c) 4 wt\% PP-g-MA

\subsection{Tensile properties}

Fig. 5. represents the stress-strain curves of the reference materials and the 70/15/15 $\mathrm{wt} \% \mathrm{HDPE} / \mathrm{PS} / \mathrm{PET}$ blends, using various production methods. The plastics applied in the study can be characterized by the following parameter: HDPE has the highest elongation at break, but the smallest tensile strength $(25.7 \mathrm{MPa})$ and Young's modulus $(0.92 \mathrm{GPa})$. The tensile strength of PET $(56.5 \mathrm{MPa})$ is the highest of the applied plastics. The value of tensile strength of PS (36.7 MPa) was between PET and HDPE. PS is a rigid polymer with a significantly higher Young's modulus (1.98 GPa) than HDPE, which is comparable with the Young's modulus of PET (2.06 GPa).

Comparing the three different blend preparing methods, it can be stated, that the way of prior homogenization with internal mixer followed by injection moulding shows the smallest elongation and the lowest mechanical properties (e.g. 24-26 MPa tensile strength), regardless of whether the blends contained compatibilizer or not (see Table 2.). Presumably, this way of production (10 minutes internal mixing, followed by injection moulding) caused the highest shear forces overall, leading to a slight degradation in 70/15/15 HDPE/PS/PET blend.

Blends without compatibilizer, produced by prior extrusion followed by injection moulding, or directly injection moulded have the highest tensile strength (30.03 $\mathrm{MPa}$ and $30.55 \mathrm{MPa}$, respectively). There was no difference in tensile strength values among the different production methods, when SEBS-g-MA was added to blends. Nevertheless, the Young's modulus of blends was significantly higher in case of direct injection moulding. The Young's moduli of blends containing SEBS-g-MA have slightly decreased, because of the softening effect of the additive.

The elongation at break occurred between $5-10 \%$ of strain in blends without compatibilizer. The break occurred every time at higher strain, when $4 \mathrm{wt} \%$ SEBS-gMA was added to the blends, while introducing PP-g-MA to the blends decreased the value of elongation at break. This suggests that PP-g-MA was not able to make a chemical interaction with the applied plastics, and when this additive is located in the boundary of the phases, the interfacial tension may be greater due to the presence of the new component. 


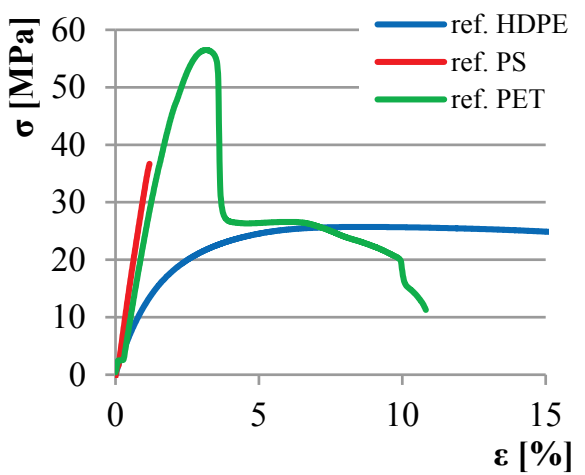

(a)

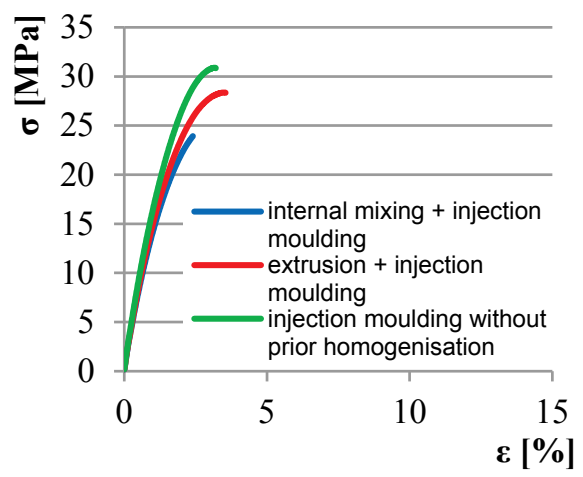

(c)

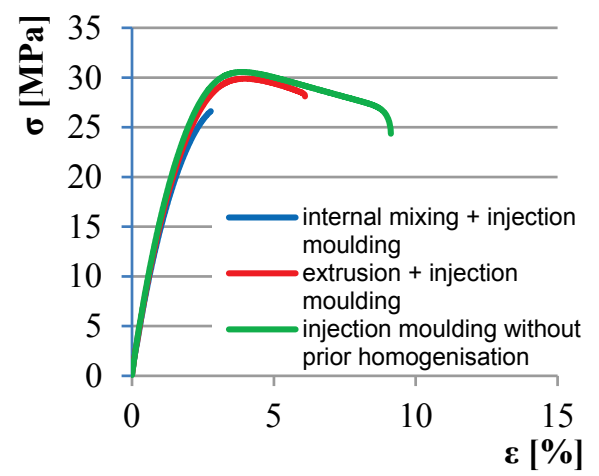

(b)

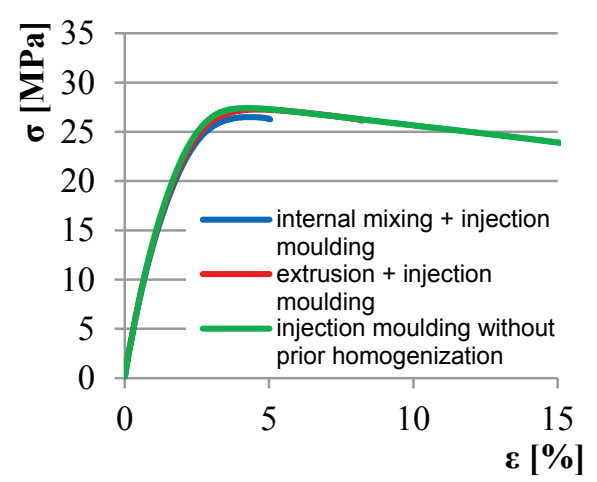

(d)

Figure 5. Stress-strain curves of reference materials and 70/15/15 wt\%

HDPE/PS/PET blends - produced by internal mixing followed by injection moulding, or extrusion followed by injection moulding, or direct injection moulding without previous homogenisation: (a) reference materials, (b) blends without compatibilizer, (c) blends with 4 wt\% PP-g-MA, (d) blends with 4 wt\% SEBS-g-MA

Despite blends consisted of $70 \mathrm{wt} \%$ HDPE, the tensile strength was slightly and the Young's modulus was significantly improved of blends than the values of HDPE reference, when prior extrusion followed by injection moulding or direct injection moulding were used (see Table 2.). Adding PS and PET to HDPE and forming a blend of these plastics can improve the strength and the modulus of HDPE. However, the elongation at break of the blends without compatibilizer has decreased. But in the case when $4 \mathrm{wt} \%$ SEBS-g-MA was added to the blends, an increase was observed in elongation at break of blends. 
Table 2. Mechanical properties of 70/15/15 HDPE/PS/PET blend with two different types of compatibilizers, prepared by three different method: prior internal mixing, followed by injection moulding; prior extrusion, followed by injection moulding or injection moulding without previous homogenisation

\begin{tabular}{|c|c|c|c|c|c|c|}
\hline & \multicolumn{3}{|c|}{ Tensile strength [MPa] } & \multicolumn{3}{|c|}{ Young's modulus [GPa] } \\
\hline & $\begin{array}{c}\text { internal } \\
\text { mixing }+ \\
\text { injection } \\
\text { moulding }\end{array}$ & $\begin{array}{c}\text { extrusion } \\
+ \\
\text { injection } \\
\text { moulding }\end{array}$ & $\begin{array}{l}\text { injection } \\
\text { moulding }\end{array}$ & $\begin{array}{l}\text { internal } \\
\text { mixing }+ \\
\text { injection } \\
\text { moulding }\end{array}$ & $\begin{array}{c}\text { extrusion } \\
+ \\
\text { injection } \\
\text { moulding }\end{array}$ & $\begin{array}{l}\text { injection } \\
\text { moulding }\end{array}$ \\
\hline $70 / 15 / 15$ & $\begin{array}{l}26.47 \\
\pm 0.27\end{array}$ & $\begin{array}{l}30.03 \\
\pm 0.12\end{array}$ & $\begin{array}{l}30.55 \\
\pm 0.09\end{array}$ & $\begin{array}{c}1.13 \\
\pm 0.009 \\
\end{array}$ & $\begin{array}{c}1.19 \\
\pm 0.010 \\
\end{array}$ & $\begin{array}{c}1.44 \\
\pm 0.002 \\
\end{array}$ \\
\hline $\begin{array}{l}70 / 15 / 15 \\
+4 \% \\
\text { SEBS-g-MA }\end{array}$ & $\begin{array}{l}26.25 \\
\pm 0.35\end{array}$ & $\begin{array}{l}27.54 \\
\pm 0.24\end{array}$ & $\begin{array}{l}27.43 \\
\pm 0.15\end{array}$ & $\begin{array}{c}1.06 \\
\pm 0.013\end{array}$ & $\begin{array}{c}1.10 \\
\pm 0.009\end{array}$ & $\begin{array}{c}1.23 \\
\pm 0.014\end{array}$ \\
\hline $\begin{array}{l}70 / 15 / 15 \\
+4 \% \\
\text { PP-g-MA }\end{array}$ & $\begin{array}{l}23.97 \\
\pm 0.31\end{array}$ & $\begin{array}{l}28.36 \\
\pm 0.11\end{array}$ & $\begin{array}{l}30.28 \\
\pm 0.66\end{array}$ & $\begin{array}{c}1.12 \\
\pm 0.004\end{array}$ & $\begin{array}{c}1.17 \\
\pm 0.007\end{array}$ & $\begin{array}{c}1.24 \\
\pm 0.019\end{array}$ \\
\hline
\end{tabular}

\subsection{Impact strength}

The Charpy impact strength of the 70/15/15 wt \% HDPE/PS/PET blend is shown on Fig. 6. Comparing the mixtures, it can be stated, that blends containing PP-g-MA were more rigid, than blends without compatibilizer, and easily broke during the tests, regardless of the three ways of production of the blend. This behaviour is in good agreement with the results of tensile tests. By investigating the various processing methods, it can be stated that blends, produced by internal mixer followed by injection moulding have smaller impact strength in every case, than the samples which were produced by the two other methods.

Comparing the two different types of compatibilizers, it is visible, that the impact strength of the blends which contain SEBS-g-MA is more than three times higher, if they were produced by prior extrusion followed by injection moulding or only injection moulding, which suggests that SEBS-g-MA was able to connect with the phases of the blend. In contrast, as it was described above, the PP-g-MA might increase the interfacial tension when it is located in boundary of the blend phases. With the additive a coarse morphological structure was formed in blends - against SEBS-g-MA -, which resulted in a slight decrease of the impact strength of 70/15/15 HDPE/PS/PET blend. 


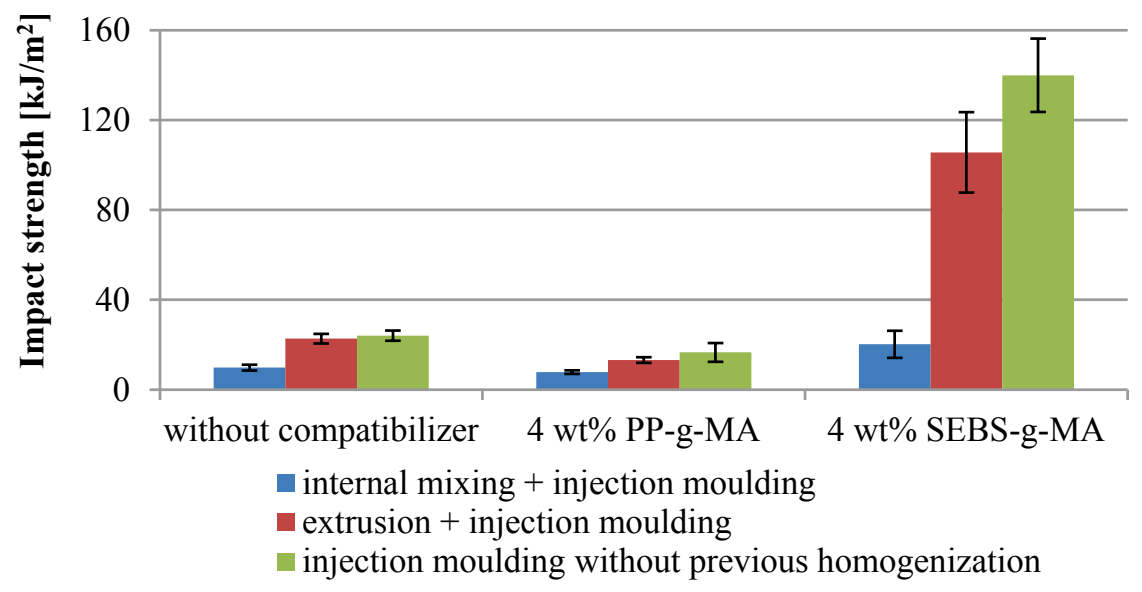

Figure 6. Charpy impact strength of 70/15/15 wt\% HDPE/PS/PET ternary blend without compatibilizer, with $4 \mathrm{wt} \%$ PP-g-MA and $4 \mathrm{wt} \%$ SEBS-g-MA compatibilizer; produced by different methods: internal mixing followed by injection moulding, or extrusion followed by injection moulding, or injection moulding without previous homogenisation

\section{Conclusion}

In this research the mechanical and morphological properties of the 70/15/15 wt $\%$ HDPE/PS/PET blend were investigated, when various processing methods and compatibilizers were applied. The tensile strength and Young's modulus of HDPE can be improved, if PS and PET were added to it. Based on the research, the best mechanical properties of the blend can be achieved, when the blends were prepared with extrusion followed by injection moulding or direct injection moulding, and $4 \mathrm{wt} \%$ SEBS-g-MA had been added to the blend. In case of SEBS-g-MA contained HDPE/PS/PET blend the fracture occurred at higher elongation, and the impact strength was also increased in a large extent, without significant decrease of tensile strength and Young Modulus. It has been also demonstrated, that improper selection of additives could reduce the elongation at break and impact properties of blends, without improving other mechanical properties. The results can provide a good guidance for industrial utilisation.

\section{Acknowledgement}

This research was realized in the frames of TÁMOP 4.2.4. A/1-11-1-2012-0001 "National Excellence Program - Elaborating and operating an inland student and researcher personal support system". The project was subsidized by the European Union and co-financed by the European Social Fund. The infrastructure of the research project was supported by the Hungarian Scientific Research Fund (OTKA K109224). 


\section{References}

[1] Al-Salem SM, Lettieri P, Baeyens J: Recycling and recovery routes of plastic solid waste (PSW): A review. Waste Management, Vol. 29, No. 10, pp. 2625-2643, 2009.

DOI: $10.1016 /$ j.wasman.2009.06.004

[2] Sperling LH: Introduction to physical polymer science. 4th ed. John Wiley \& Sons Inc., Hoboken, 2006.

[3] Manias E, Utracki LA: Chapter 2 - Thermodynamics of polymer blends. in Polymer blends handbook. Eds: Utracki LA, Wilkie CA, Springer, Dordrecht, Vol 1 (2nd ed), 171-289, 2014.

[4] Li Y-Y, Hu S-W, Sheng J: Evolution of phase dimensions and interfacial morphology of polypropylene/polystyrene compatibilized blends during mixing. European Polymer Journal, Vol. 43, No. 2, pp. 561-572, 2007.

DOI: $10.1016 /$ j.eurpolymj.2006.10.018

[5] Hargitai H, Ibriksz T, Stifter J, Andersen E: Development of PA6/HDPE nanocomposite blends. Materials Science Forum, Vol. 729, pp. 216-221, 2013. DOI: $10.4028 /$ www.scientific.net/MSF.729.216

[6] Razavi S, Shojaei A, Bagheri R: Binary and ternary blends of high-density polyethylene with poly(ethylene terephthalate) and polystyrene based on recycled materials. Polymers for Advanced Technologies, Vol. 22, No. 5, pp. 690-702, 2011.

DOI: $10.1002 /$ pat.1567

[7] Omonov TS, Harrats C, Groeninckx G: Co-continuous and encapsulated three phase morphologies in uncompatibilized and reactively compatibilized polyamide 6/polypropylene/polystyrene ternary blends using two reactive precursors. Polymer, Vol. 46, No. 26, 12322-12336, 2005.

DOI: $10.1016 /$ j.polymer.2005.10.022

[8] Yin B, Li L-P, Yan Z, Gong L, Yang M-B, Xie B-H: Largely improved impact toughness of PA6/EPDM-g-MA/HDPE ternary blends: The role of core-shell particles formed in melt processing on preventing micro-crack propagation. Polymer, Vol. 54, No. 7, pp. 1938-1947, 2013.

DOI: $10.1016 /$ j.polymer.2013.02.001

[9] Fayt R, Jerome R, Teyssié P: Molecular design of multicomponent polymer systems, 13. Control of the morphology of polyethylene/polystyrene blends by block copolymers. Die Makromolekulare Chemie, Vol. 187, No. 4, pp. 837-852, 1986.

DOI: $10.1002 / \mathrm{macp} .1988 .021890726$

[10] Imre B, Renner K, Pukánszky B: Interactions, structure and properties in poly(lactic acid)/thermoplastic polymer blends. eXPRESS Polymer Letters, Vol. 8, No. 1, pp. 2-14, 2014.

DOI: $10.3144 /$ expresspolymlett.2014.2

[11] Ravati S, Favis BD: Morphological states for a ternary polymer blend demonstrating complete wetting. Polymer, Vol. 51, No. 20, pp. 4547-4561, 2010. DOI: $10.1016 /$ j.polymer.2010.07.014 
[12] Dobrovszky K, Ronkay F: Alternative polymer separation technology by centrifugal force in a melted state. Waste Management, Vol. 34, No. 11, pp. 21042112, 2014.

DOI: 10.1016/j.wasman.2014.05.006

[13] Pötschke P, Paul DR: Formation of Co-continuous Structures in Melt-Mixed Immiscible Polymer Blends. Journal of Macromolecular Science, Part C: Polymer Reviews, Vol. 43, No. 1, pp. 87-141, 2003.

DOI: $10.1081 / \mathrm{MC}-120018022$

[14] Wang D, Li Y, Xie X-M, Guo B-H: Compatibilization and morphology development of immiscible ternary polymer blends. Polymer, Vol. 52, No. 1, pp. 191-200, 2011.

DOI: $10.1016 /$ j.polymer.2010.11.019

[15] Pracella M, Rolla L, Chionna D, Galeski A: Compatibilization and properties of poly(ethylene terephthalate)/polyethylene blends based on recycled materials. Macromolecular Chemistry and Physics, Vol. 203, No. 10-11, pp. 1473-1485, 2002.

DOI: $10.1002 / 1521-3935(200207) 203: 10 / 11<1473:: A I D-M A C P 1473>3.0 . C O ; 2-4$

[16] Sahnoune F, Lopez Cuesta JM, Crespy A: Improvement of the mechanical properties of an HDPE/PS blend by compatibilization and incorporation of $\mathrm{CaCO}_{3}$. Polymer Engineering \& Science, Vol. 43, No. 3, pp. 647-660, 2003.

DOI: $10.1002 /$ pen.10053

[17] Carté TL, Moet A: Morphological origin of super toughness in poly(ethylene terephthalate)/polyethylene blends. Journal of Applied Polymer Science, Vol. 48, No. 4, pp. 611-624, 1993.

DOI: $10.1002 /$ app.1993.070480405 